\title{
New Approach of Ultrasound-Guided Genitofemoral Nerve Block in Addition to Ilioinguinal/Iliohypogastric Nerve Block for Surgical Anesthesia in Two High Risk Patients: Case Report
}

\author{
Achir A. Al-Alami, Mahmoud S. Alameddine, Mohammed J. Orompurath
}

Anesthesia Department, International Medical Center, Jeddah, KSA.

Email: achiralami@gmail.com

Received April 20 ${ }^{\text {th }}, 2013$; revised May 20 ${ }^{\text {th }}, 2013$; accepted June $15^{\text {th }}, 2013$

Copyright (c) 2013 Achir A. Al-Alami et al. This is an open access article distributed under the Creative Commons Attribution License, which permits unrestricted use, distribution, and reproduction in any medium, provided the original work is properly cited.

\begin{abstract}
We report two high risk patients undergoing inguinal herniorraphy and testicular biopsy under ultrasound-guided ilioinguinal/iliohypogastric and genitofemoral nerve blocks. The addition of the genitofemoral nerve block may enhance the ilioinguinal/iliohypogastric block to achieve complete anesthesia and thus avoid general and neuraxial anesthesia related hypotension that may be detrimental in patients with low cardiac reserve.
\end{abstract}

Keywords: Nerve Block; Ultrasound; Genitofemoral Nerve; Ilioinguinal Nerve; Iliohypogastric Nerve; Testicle Biopsy; Inguinal Hernia

\section{Introduction}

The high incidence of chronic post-surgical pain associated with inguinal hernia repair is well documented [1,2]. The technical difficulty in identifying and selectively blocking the nerves concerned makes the subject to be studied in detail. In particular ilioinguinal/iliohypogastric (II/IH) nerve block has widely been used for inguinal hernia repair. The sensory innervations from genitofemoral (GF) nerve to the inguinal region may provide insufficient analgesia by this technique for intra- and postoperative pain management. Therefore, an addition of genitofermoral nerve block that improves the quality of analgesia is proposed.

\section{Case Report}

\subsection{Case 1}

A 76-year-old gentleman with past medical history of end-stage renal disease on dialysis, systemic hypertension, severe pulmonary hypertension and interstitial lung disease was scheduled to undergo a left open inguinal herniorraphy with mesh. His body weight was $50 \mathrm{~kg}$ and the preoperative coagulation profile was within normal limit except platelet count of 80,000. Ultrasound-guided
II/IH and GF nerve blocks were planned for anesthesia.

Patient was placed in supine position, with standard American society of Anesthesiology (ASA) monitors in place. Face mask oxygen was supplemented at $5 \mathrm{lt} / \mathrm{min}$. Intravenous (i.v) sedation was given using propofol: ketamine mixture in the ratio $4: 1$ infused at $5 \mathrm{ml} / \mathrm{hr}$. The local anesthetic (LA) mixture constituted of $2 \%$ lidocaine with $0.5 \%$ bupivacaine mixed at ratio $1: 1$ with the addition of epinephrine $1 / 400,000$.

The left inguinal area was prepped with $70 \%$ alcohol and iodine. A linear probe with $10 \mathrm{~Hz}$ frequency with depth of $2.5 \mathrm{~cm}$ was used for scanning (Ultrasonix, Sonix, Richmond, Canada).

For II/IH block, the ultrasound probe covered with sterile sheath was placed at the anterior superior iliac spine (ASIS) in oblique fashion at the line joining the umbilicus and the ASIS. The two muscles, the internal oblique and transverses abdominis were in view (Figure 1). A 22 G spinal Quincke needle (Madrid, Spain) was introduced in-plane; hydro-dissection technique with normal saline was used to localize the needle tip. After negative aspiration $20 \mathrm{ml}$ of the LA was deposited between transverse abdominis and internal oblique; and between internal and external oblique muscles.

For GF block, the ultrasound probe was placed parallel 


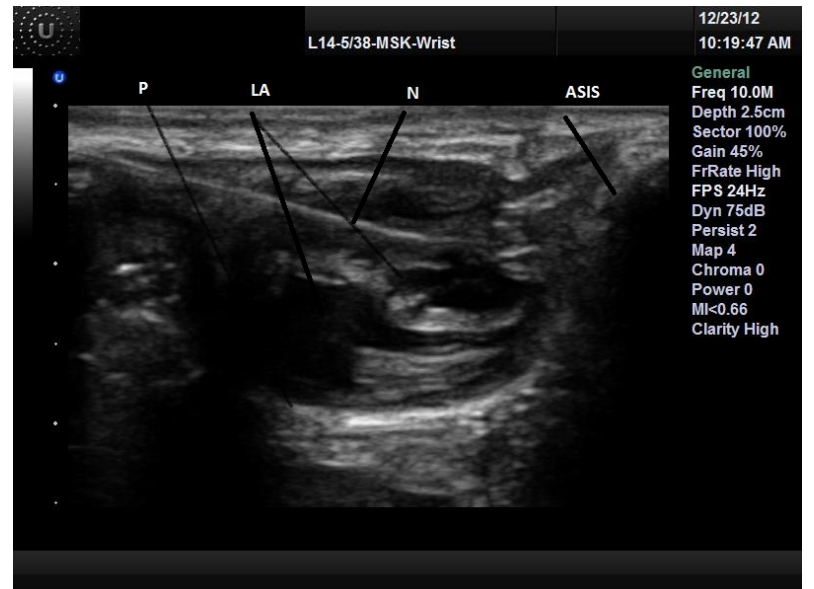

N: Needle; ASIS: Anterior superior iliac spine; LA: Local anesthesia; P: Peritoneum.

Figure 1. II/IH nerve block.

and $1.25 \mathrm{~cm}$ above the inguinal ligament scanning over the external iliac artery (EIA) and vein. At this location the probe was tilted slightly cephalad to visualize the inferior epigastric artery (IEA) that is emerging medially from the EIA (Figure 2). The needle was introduced in-plane from the lateral end of the probe until the needle tip was at the lateral vicinity of the IEA; $20 \mathrm{ml}$ of LA was deposited after negative aspiration.

At the beginning of surgery patient felt mild pain that was relieved by $50 \mathrm{mcg}$ i.v fentanyl. Surgery was uneventful and sedation was discontinued towards the skin closure. Patient felt no pain postoperatively and received only $500 \mathrm{mg}$ i.v paracetamol before he was discharged home next day.

\subsection{Case 2}

A 55-year-old gentleman with past medical history of congestive heart failure with ejection fraction of $15 \%$, body weight of $100 \mathrm{~kg}$ was scheduled to undergo a bilateral testicular biopsy for fertility diagnosis. Ultrasoundguided bilateral II/IH and GF nerve blocks were planned for anesthesia.

The lower abdomen skin was prepped with iodine with $70 \%$ alcohol. After applying full ASA monitoring, propofol with ketamine mixture in the ratio 4:1 was infused at $10 \mathrm{ml} / \mathrm{hr}$ for sedation. II/IH and GF nerve blocks were performed in the same way as described in Case 1 except that the scanning depth was $4.5 \mathrm{~cm}$. The same mixture of LA as in Case 1 with total of $60 \mathrm{ml}$ was divided into 4 , for each block.

Right testicle biopsy was obtained without problems (Figure 3). During left testicle biopsy, the patient felt some pain at the dissection of Dartos fascia which was relieved by $50 \mathrm{mcg}$ i.v fentanyl. Towards the end of surgery sedation was discontinued and patient was trans-

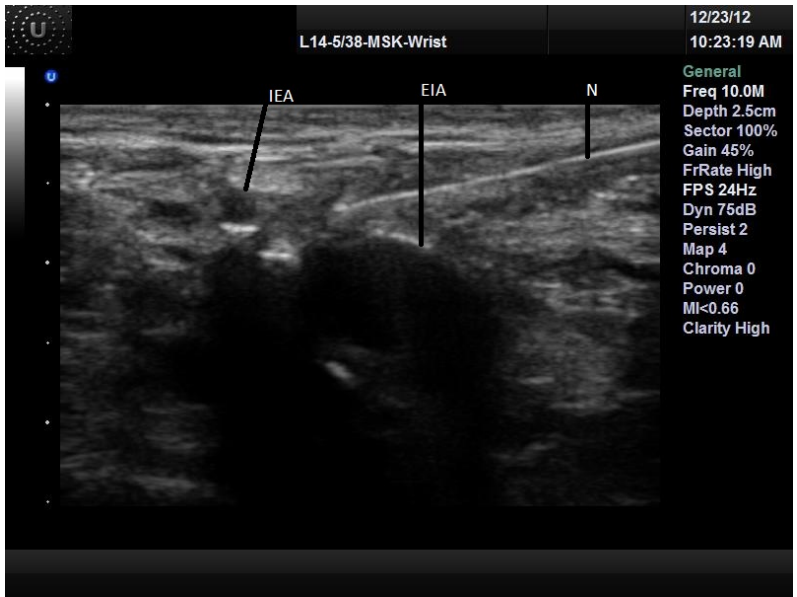

N: Needle; IEA: Inferior epigastric artery; EIA: External iliac artery.

Figure 2. Genital branch GF block.

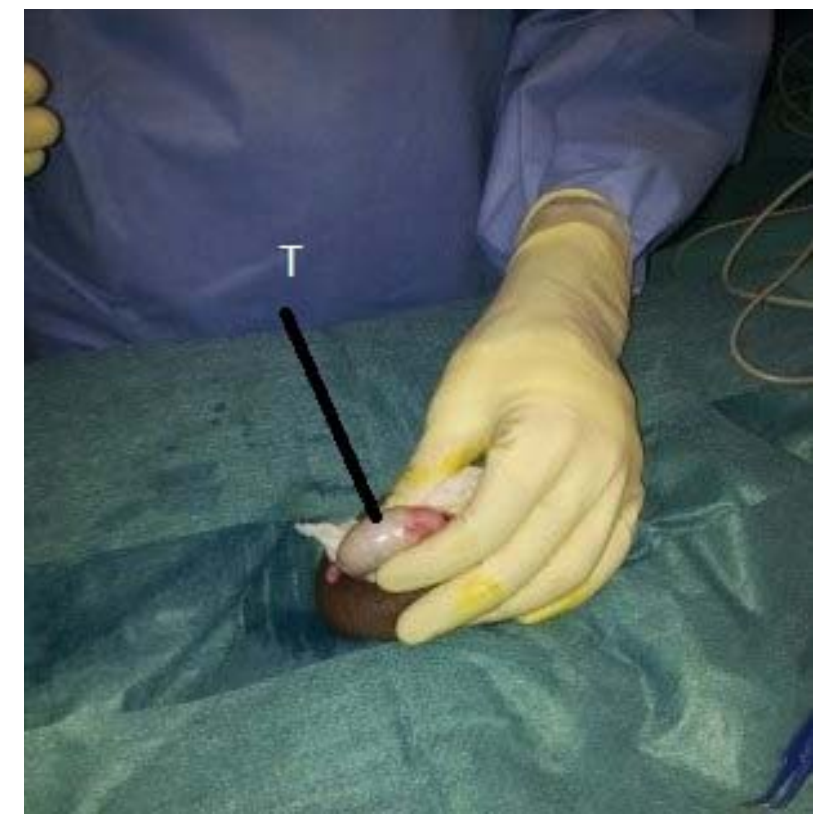

T: Testis.

Figure 3. Open testicular biopsy.

ferred to the recovery room. In the postoperative period, the patient did not complain of any pain and requested no analgesics; two hours later he was discharged home with oral analgesics.

\section{Discussion}

The II nerve originates from L1; as a part of lumbar plexus it emerges from the lateral border of the psoas muscle and crosses obliquely over the quadratus lumborum muscle, piercing the transversus abdominis then the internal oblique muscles near the anterior superior iliac spine, entering the inguinal canal giving an end to sensory branch in the inguinal region and the scrotum 
[3].

The GF nerve originates from L1 and L2 as a part of lumbar plexus within the psoas muscle. It emerges on the anterior surface of the psoas caudally, crossing obliquely behind the ureter and dividing above the inguinal ligament into genital and femoral branches [4]. The genital branch enters the inguinal canal within the spermatic cord through the deep inguinal ring lateral to the IEA at 1 $-1.5 \mathrm{~cm}$ above the inguinal ligament, giving both motor and sensory innervations to the cremaster muscle and anterolateral aspect of the scrotum respectively [5].

In the first case, genital branch of GF nerve was blocked during inguinal herniorraphy to decrease paininduced by traction of the hernia sac [6].

In the second case, the biopsies were taken through a cut in the anterior surface of the scrotum so only II and GF nerves were needed to be anesthetized. The scrotum is innervated anteriorly by the genital branch of GF nerve and branches from the II nerve, posteriorly by branches of the pudendal nerve and inferiorly by branches from the posterior femoral cutaneous nerve. The testis is innervated by the sympathetic nerves from T7 [7].

II/IH nerve block has been described using both anatomical landmark technique and ultrasound guidance [8]. GF nerve block has been described using either paravertebral block at level of L2 or field block at the level of pubic tubercle [7,9].

Ultrasound-guided GF block has been described in chronic pain management for both genital and femoral branches [1,2]. In the genital branch US-guided GF block the authors describe it differently than us; they suggest longitudinal scanning over the femoral artery at the internal inguinal ring and moving the probe cephalad when the artery dives deeply. At this point the probe is moved slightly medially till the spermatic cord superficial to the femoral artery is seen with injection done out-of-plane [1]. On the other hand to localize the nerve, we rely on visualizing the EIA and the IEA rather than the spermatic cord that looks hazy in ultrasound.

In conclusion, we describe an ultrasound-guided GF nerve block of genital branch in addition to II/IH nerve block for surgical anesthesia. The advantages of using this technique are enhancing the anesthesia of II/IH block in inguinal hernia and testicular surgery and avoiding hypotension associated with general and neuraxial anes- thesia. However further future prospective clinical studies are deemed necessary to evaluate this technique.

\section{REFERENCES}

[1] P. W. Peng and P. S. Tumber, "Ultrasound-Guided Interventional Procedures for Patients with Chronic Pelvic Pain-A Description of Techniques and Review of Literature,” Pain Physician, Vol. 11, No. 2, 2008, pp. 215224.

[2] N. A. Campos, J. H. Chiles and A. R. Plunkett, "Ultrasound-Guided Cryoablation for Genitofemoral Nerve for Chronic Inguinal Pain,” Pain Physician, Vol. 12, No. 6, 2009, pp. 997-1000.

[3] K. L. Moore and A. F. Dailey, "Clinical Oriented Anatomy,” 4th Edition, Lippincott Williams \& Wilkins, Philadelphia, 1999, p. 300.

[4] K. L. Moore and A. F. Dailey, "Clinical Oriented Anatomy,” 4th Edition, Lippincott Williams \& Wilkins, Philadelphia, 1999, p. 530.

[5] S. Standring, H. Ellis, J. C. Healy, D. Johnson, A. Williams and P. Collins, “Gray’s Anatomy,” 39th Edition, Elsevier Churchill Livingstone, Edinburgh, 2005, p. 1125.

[6] N. Sasaoka, M. Kawaguchi, K. Yoshitani, H. Kato, A. Suzuki and H. Furuya, "Evaluation of Genitofemoral Nerve Block, in Addition to Ilioinguinal and Iliohypogastric Nerve Block, during Inguinal Hernia Repair in Children,” British Journal of Anaesthesia, Vol. 94, No. 2, 2005, pp. 243246. doi:10.1093/bja/aei031

[7] K. L. Moore and A. F. Dailey, "Clinical Oriented Anatomy,” 4th Edition, Lippincott Williams \& Wilkins, Philadelphia, 1999, pp. 201-202.

[8] M. Weintraud, M. Lundblad, S. C. Kettner, H. Willschke, S. Kapral, P. A. Lonqvist, et al., "Ultrasound versus Landmark-Based Technique for Ilioinguinal-Iliohypogastric Nerve Blockade in Children: The Implications on Plasma Levels of Ropivacaine,” Anesthesia \& Analgesia, Vol. 108, No. 5, 2009, pp. 1488-1492. doi:10.1213/ane.0b013e31819cb1f3

[9] Z. M. Naja, M. Raf, M. El Rajab, F. M. Ziade, M. A. Al Tannir and P. A. Lonnqvist, "Nerve Stimulator-Guided Paravertebral Blockade Combined with Sevoflurane Sedation versus General Anesthesia with Systemic Analgesia for Postherniorrhaphy Pain Relief in Children: A Prospective Randomized Trial,” Anesthesiology, Vol. 103, No. 3, 2005, pp. 600-605. doi:10.1097/00000542-200509000-00024 